\title{
Feasibility Study of the Enhancing Parenting Skills Programme
}

\author{
Margiad E. Williams $\mathbb{B}^{1} \cdot$ Zoe Hoare $^{2} \cdot$ Dawn A. Owen $^{1} \cdot$ Judy Hutchings ${ }^{1}$
}

Published online: 25 September 2019

(c) The Author(s) 2019

\begin{abstract}
Objectives This study reports on the feasibility and initial effectiveness of an individually delivered parent programme for parents of young children with behaviour problems. Whilst parenting programmes are known to be effective in reducing behaviour problems, numerous barriers can prevent families from accessing programmes. Individually delivered parent programmes may be more accessible. In the UK, health visitors provide support to all families with a child under 5 years of age and are ideally placed to deliver interventions for child behaviour problems.

Methods Fifty-eight parents reporting children with behaviour problems were recruited from four areas to intervention $(n=$ $29)$ and treatment as usual, wait-list control $(n=29)$ conditions. Feasibility outcomes included recruitment, retention, programme delivery, and satisfaction. Baseline and six-month post-randomisation follow-up measures were collected in parents' homes and included parent-report measures of child behaviour, parenting skills, and parental mental health as well as an observation of parenting behaviour during a parent-child play task.

Results Significant changes in child behaviour, lax parenting, and parental mental health were found for the whole sample but there were no significant differences between conditions. Recruitment and retention rates were lower than expected questioning the feasibility of delivering the parent programme as it is in existing services.

Conclusions This paper provides limited evidence for the feasibility of the Enhancing Parenting Skills programme delivered in existing health services. Further feasibility work, particularly for recruitment and retention, would be needed before conducting a larger study to examine the effectiveness of the programme.
\end{abstract}

Keywords Parenting $\cdot$ Child behaviour $\cdot \mathrm{RCT} \cdot$ Feasibility $\cdot$ Individual treatment

Globally, the most common mental disorders in children are behavioural problems, with a worldwide estimated prevalence of 5.7\% (Polanczyk et al. 2015). In the UK, they are the most common reason for referral to Child and Adolescent Mental Health Services (CAMHS) and cost society thousands of pounds every year (National Collaborating Centre for Mental Health [NCCMH] 2013; Rivenbark et al. 2018). Numerous risk factors have been identified for the development of child behaviour problems, including individual factors such as child gender or temperament (Martel 2013; Miner and Clarke-Stewart 2008), and familial/social

Margiad E. Williams

margiad.williams@bangor.ac.uk

1 Centre for Evidence Based Early Intervention, Nantlle Building, Normal Site, Bangor University, Bangor LL57 2PZ, UK

2 North Wales Organisation for Randomised Trials in Health and Social Care, Bangor University, Bangor LL57 2PZ, UK factors such as poverty (Shaw and Shelleby 2014). However, despite there being a range of factors correlated with increased risk for children, it is the extent to which these risk factors compromise parenting that predicts child behaviour problems (Gach et al. 2018; Hoeve et al. 2009).

The most effective interventions to address child behaviour problems are parenting programmes that teach appropriate behaviour management skills based on social learning theory principles (Furlong et al. 2012; NCCMH 2013). Many evaluations have shown significant improvements in child behaviour, parenting skills, and parental mental health (Barlow and Coren 2018). Changes in parenting have also been shown to mediate changes in child behaviour (Gach et al. 2018). Parenting programmes typically teach parents positive strategies (e.g., praise, rewards, clear instructions and household rules) to encourage positive child behaviours, and behaviour management strategies such as ignoring to reduce the incidence of child behaviour problems. Parents are also taught the importance of spending time playing and/or in special time activities with 
their children to encourage the development of strong parent-child relationships. Video clips and modelling are used in many programmes to demonstrate the behavioural skills being taught, and parents are given the opportunity to practice implementing these skills through role-play or in home-based practice with their children. Some, particularly the more effective programmes, use homework tasks designed to promote skill development at home (Kaminski et al. 2008). A number of effective programme components have been identified including positive interactions with their child, active rehearsal of skills, teaching of principles not techniques, modelling, and time-out (e.g., Barth and Liggett-Creel 2014; Kaminski et al. 2008).

Parenting programmes can be delivered in several formats including group-based, individual, and self-administered. However, there are practical and psychological obstacles that often prevent families from accessing parenting programmes (e.g., financial costs, transportation, stigma, work schedules) (Duppong-Hurley et al. 2016; Heath et al. 2018; Lavigne et al. 2010; Sayal et al. 2010). Parents' perceptions of barriers associated with parenting programmes, demands imposed by the intervention, relevance, and their relationship with the provider can also have an effect (Kazdin 1997). Individually delivered parenting programmes overcome some of the practical barriers because they can be delivered in the family home, making them potentially more accessible, and by a professional with which the parent already has a good relationship (Kazdin 1997; Lundahl et al. 2006; Reyno and McGrath 2006). Individually administered parenting programmes have stronger effects in reducing child behaviour problems compared to groupbased programmes, especially for vulnerable parents (Lundahl et al. 2006). This may be due to the inclusion of live coaching of skills with parents and children, a component which has been shown to be effective in teaching behavioural techniques (Kaminski et al. 2008). Vulnerable families are also more likely to have complex needs and may benefit more from individually focussed interventions (Hutchings and Williams 2019).

Parenting programmes are typically delivered by professionally trained staff including clinical psychologists, health visitors/public health nurses, and social workers. Health visitors in the UK are trained nurses with specialist training in public health promotion, including a specific focus on the factors associated with positive child development. They provide a universal service to all families with children under the age of 5 years, known as the Healthy Child Programme, and targeted services for those in need (e.g., vulnerable families) (Cowley et al. 2007; Department of Health 2009). The recommended caseload size for each health visitor is approximately 250 families but caseloads are often much larger (Munday 2018). As part of a universal service, there are a minimum of five mandated visits that health visitors are required to complete with all families, including an ante-natal visit, new baby review at two weeks, six- to eight-week assessment, 12-month assessment, and a 27-month assessment. The majority of parents are not seen by their health visitor after the 27 -month visit unless there is an identified need. Vulnerable families receive additional support from their health visitor including for issues such as sleep, behaviour, and feeding. For all health visitors, approximately $9 \%$ of their caseloads would require additional support at some point in the child's life, up until the age of 5 years (Munday 2018).

A trusting parent-practitioner relationship is vital for working with vulnerable families, and the close one-to-one contact through home visits that health visitors provide places them in a good position to develop a meaningful understanding of family needs (Whittaker 2014). Health visitors are a valued source of advice for parents who especially value their knowledge of parenting, child development and behaviour (Brook and Salmon 2017; Hogg et al. 2013). Their knowledge of child development and access to all families of young children makes them ideally placed to deliver parenting interventions (Cowley et al. 2013; Myors et al. 2014). A survey of health visitor skills showed that they typically use some evidence-based behavioural techniques as part of their work with families, but most were non-specific and not in the form of a structured intervention (Williams and Hutchings 2018). Many health visitors report growing caseloads of children with behaviour difficulties, and spend a lot of time dealing with these cases (Wilson et al. 2008), suggesting that a structured intervention may be a useful tool for working with families.

Due to the heavy demand on health visitors, the Enhancing Parenting Skills (EPaS) programme was developed with the goal of training health visitors in behavioural management skills to utilise in their work with families of children with disruptive behaviours. The model was developed based on social learning theory principles with the intention of providing individualised support to families. Individualised support is the cornerstone of effective work with families experiencing significant difficulties with their children. The EPaS programme is conceptualised as a process consisting of three phases: a standardised assessment; a structured case analysis formulation process to facilitate the identification of the specific problem behaviours, their functions, and the necessary replacement behaviours; and an intervention phase designed to support parents in implementing evidence-based behaviour change strategies.

The EPaS programme was developed from an intensive coaching intervention involving video-feedback that was delivered and evaluated with families of CAMHS referred children with severe behavioural problems. Findings showed significant improvements in child behaviour, parenting, and parental mental health (Hutchings et al. 2002) 
and were maintained at a four-year follow-up (Hutchings et al. 2004). The main limitations were that it targeted CAMHS referred school-aged children with severe behavioural problems, was resource intensive, and therefore not accessible to many families. To meet the needs of more families, the programme was adapted for home delivery by health visitors with pre-school children and named the EPaS programme (Lane and Hutchings 2002). A small-scale study reported significant improvements in child behaviour and parental mental health, and health visitors reported increased confidence in and frequency of use of behavioural techniques (Lane and Hutchings 2002). However, the training delivered to the health visitors was very intensive, with sessions delivered weekly over a 12 -week period. Due to this, a further study adapted the programme for wider dissemination in the form of a two-day training for a variety of staff working with parents (Hutchings and Williams 2013). Data from a small sample showed significant reductions in child behaviour and dysfunctional parenting and improvements in parental mental well-being (Hutchings and Williams 2013). A criticism from staff on the training was that two days was too short to cover the skills needed to deliver the programme. A lack of knowledge of some staff regarding child development was another concern.

The present trial was designed to address the limitations of the previous studies and incorporate participant feedback. First, the trial reverted to the initial EPaS trial strategy of training health visitors due to the variability of child development knowledge seen in the participants of the Hutchings and Williams (2013) study and the inaccessibility of the Hutchings et al. (2002) intervention. Second, the training was revised into a three-day course due to the intensive nature of the training in the Lane and Hutchings (2002) trial and the criticism on the shortness of the training in the Hutchings and Williams (2013) study. The main aims of the present trial were to explore feasibility questions of the new EPaS training model in existing services and examine initial evidence for effectiveness. The key questions were around the feasibility of target population recruitment, intervention delivery, retention in the research study, and acceptability of the intervention to parents. Health visitor satisfaction with the training is reported elsewhere (see Williams and Hutchings 2018). Initial effectiveness was explored by comparing outcomes for families in the EPaS programme to a control condition.

\section{Methods}

\section{Participants}

Forty-nine health visitors initially consented to participate, however $12(24.5 \%)$ withdrew before commencing the EPaS training due to lack of time, personal issues, or job change. They were asked to identify two families of children aged between 30 and 60 months who were reporting having a child with significant behavioural difficulties to take part in the project. Health visitors used the Eyberg Child Behaviour Inventory (ECBI; Eyberg et al. 1980) to identify children from their caseloads who were scoring above the clinical cut-off for behaviour problems on either the Intensity $(\geq 131)$ or Problem scale $(\geq 15)$. Of the 37 health visitors who completed the EPaS training, 29 managed to identify two families for the project. All health visitors were female $(n=29 ; 100 \%)$ and had a wide range of experience (Median $=3.00$ years; range $=2$ months -28 years $).$

Eighty-seven families were approached to take part in the study. Of these, $11(12.6 \%)$ were not eligible due to scoring below the cut-off on the ECBI; eight $(9.2 \%)$ were not contacted due to their health visitor withdrawing from the study; six $(6.9 \%)$ were not randomised due to their health visitor being unable to identify a second family for the study; and four (4.6\%) were not interested in participating in the trial. Fifty-eight families were recruited and randomised to either the intervention or a treatment as usual (TAU) waitlist control condition (see CONSORT Fig. 1). Mean age of the children was 40.52 months $(S D=8.78)$ with over $70 \%$ being male. The mean score for child behaviour problems was 165.34 on the ECBI Intensity subscale, indicating significant levels above the clinical cut-off (131). All but one of the primary carers were female $(n=57 ; 98.3 \%)$ and 53 $(91.4 \%)$ were reporting living in poverty. Two-thirds of the sample were reporting three or more risk factors associated with socio-economic disadvantage (see Table 1). There were no significant differences between families in the intervention and families in the TAU control in terms of baseline characteristics. No power calculation was conducted.

\section{Procedure}

\section{Randomisation}

After collection of baseline measures, families were randomly assigned to either the intervention or the TAU control condition (ratio 1:1). Randomisation was within health visitor so that each health visitor had one intervention and one TAU control family. Randomisation occurred using an online programme with random permuted blocks (www.randomization.com).

\section{Data collection}

Ethical approval was granted by Bangor University Ethics Committee in May 2014 (application number: 2014-12886) 
Fig. 1 CONSORT diagram of participants

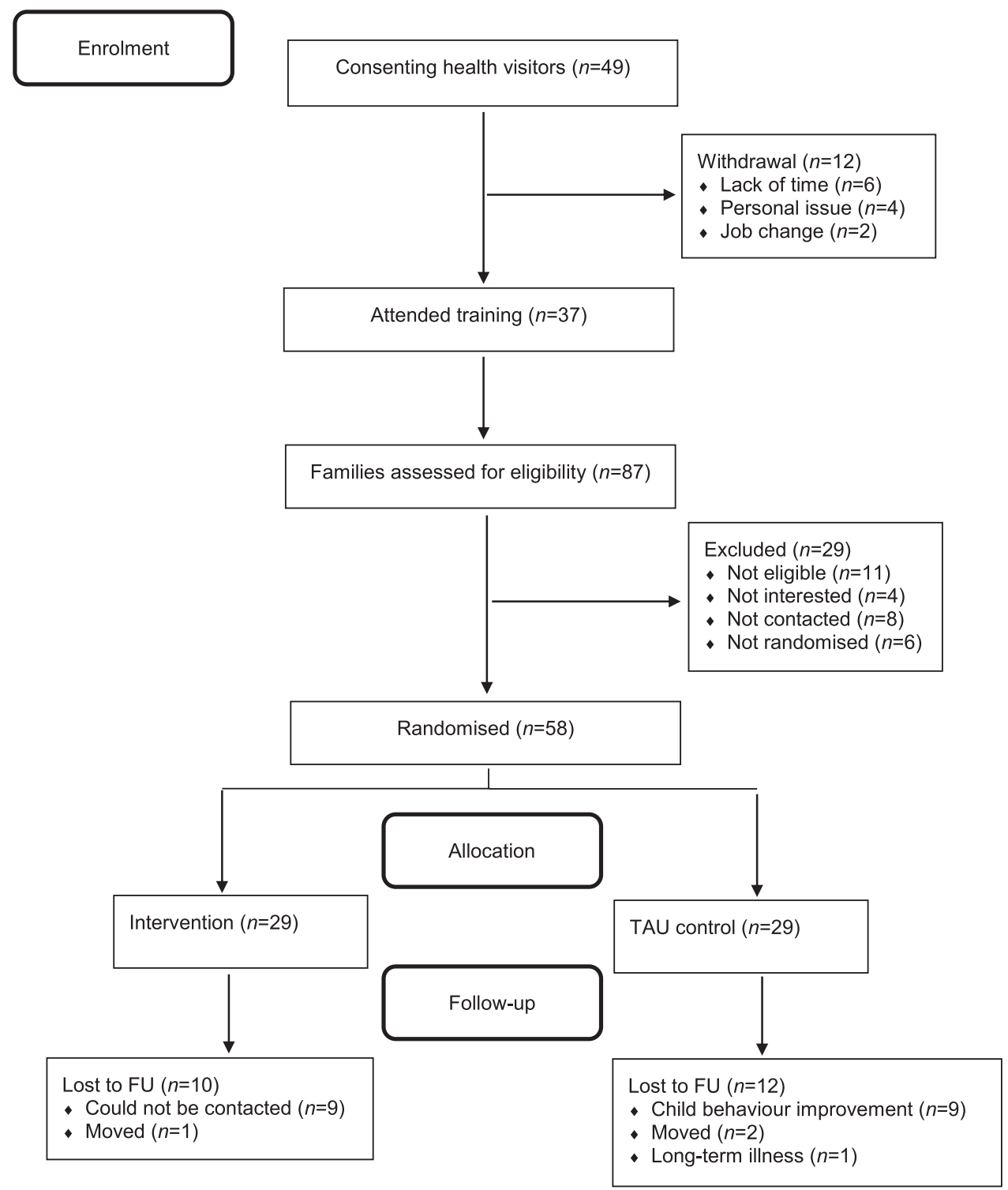

and the North West Wales Research Ethics Committee in July 2014 (application number: 14/WA/0187). The study was registered with ISRCTN (ISRCTN06867279). Families were initially approached by their health visitor to examine eligibility using the ECBI questionnaire. The families approached were from the health visitors' own caseloads and they would have had previous contact with the family. Eligible families were informed of the study and asked if they would be interested in taking part (see Fig. 1 for flow of participants through the study). Interested families completed a note of interest which was sent to the research team. The parent would then be contacted within one week to arrange a home visit. During the home visit, the study was explained in detail and any questions from parents were answered. If the parent was happy to continue, written informed consent was obtained. Only once informed consent was obtained did the parent complete the baseline measures and observation. Home visits to collect data were conducted at baseline and six months later for follow-up measures. Parents received a children's book at each timepoint as a thank you for providing data. Four families $(7 \%)$ completed the parent-child observation in Welsh while the rest were completed in English.

\section{Intervention}

All health visitors received three days of training, each day approximately one month apart. The training was delivered by the last author, an experienced clinician who developed the programme. All intervention resources were provided including a detailed manual and assessment tools (see Hutchings and Williams 2019). The programme has three phases. The first phase consists of assessment procedures that are completed with the parents. These entail 
Table 1 Participant baseline characteristics

\begin{tabular}{|c|c|c|c|}
\hline Health visitor characteristics & All $(N=29)$ & & \\
\hline Age, years: $M(S D)$ & $41.76(8.86)$ & & \\
\hline Gender, female: $n(\%)$ & $29(100.0)$ & & \\
\hline \multirow[t]{2}{*}{ HV experience, years: Median (range) } & $3.00(0-28)$ & & \\
\hline & All $(N=58)$ & Intervention $(n=29)$ & Control $(n=29)$ \\
\hline \multicolumn{4}{|l|}{ Child characteristics } \\
\hline Child gender, male: $n(\%)$ & $42(72.4)$ & $20(69.0)$ & $22(75.9)$ \\
\hline Child age, months: $M(S D)$ & $40.52(8.78)$ & $39.52(9.09)$ & $41.52(8.51)$ \\
\hline Child behaviour, ECBI: $M(S D)$ & $165.34(28.68)$ & $167.62(30.07)$ & $163.07(27.56)$ \\
\hline \multicolumn{4}{|l|}{ Parent characteristics } \\
\hline Parent gender, female: $n(\%)$ & $57(98.3)$ & $29(100.0)$ & $28(96.6)$ \\
\hline Parent age, years: $M(S D)$ & $30.55(8.90)$ & $29.07(8.02)$ & $32.03(9.61)$ \\
\hline Age birth 1st child, years: $M(S D)$ & $21.80(5.59)$ & $21.45(5.12)$ & $22.19(6.13)$ \\
\hline Low education ${ }^{\mathrm{a}}: n(\%)$ & 45 (77.6) & $23(79.3)$ & $22(75.9)$ \\
\hline Living in poverty ${ }^{\mathrm{b}}: n(\%)$ & $53(91.4)$ & $27(93.1)$ & $26(90.0)$ \\
\hline Single parent: $n(\%)$ & $19(32.8)$ & $12(41.4)$ & $7(24.1)$ \\
\hline Unemployment: $n(\%)$ & $29(50.0)$ & $16(55.2)$ & $13(44.8)$ \\
\hline Depression $^{\mathrm{c}}: n(\%)$ & $35(60.3)$ & $17(58.6)$ & $18(62.1)$ \\
\hline High risk index ${ }^{\mathrm{d}}: n(\%)$ & $39(67.2)$ & $20(69.0)$ & $19(65.5)$ \\
\hline
\end{tabular}

$H V$ health visitor, ECBI Eyberg Child Behavior Inventory Intensity subscale

${ }^{a}$ Left education before or at 16 years

${ }^{\mathrm{b}}$ Income less than 60\% median based on Office for National Statistics (2014)

cPresence of depression indicated by scoring borderline or above on BDI

${ }^{\mathrm{d}}$ Three or more risk factors standardised assessment tools including parent-report questionnaires, interview schedules, and observation tools to collect information about the family, their current circumstances, specific child problem behaviours, and parents' goals. The second phase consists of teaching the implementer how to produce a case analysis using the information collected in the assessment sessions. It involves using the information to develop an understanding of the problem, its history and current function, the assets available in the situation that will support change, and some potential short- and longer-term goals. The case analysis is shared with the family and an intervention contract is negotiated. The third phase of the programme introduces strategies that parents could use to achieve their short- and longer-term goals. Health visitors coach parents in the use of the strategies during home visits. Intervention strategies focus on improving parentchild relationships and teaching replacement behaviours (e.g., praise and rewards, ignoring unwanted behaviours, redirecting, consequences, time-out).

Parents are involved throughout the EPaS process; they are asked to keep records throughout the process including information about their child during the assessment phase. They are also asked to undertake homework assignments that clarify whether the intervention strategies are being effective. These records and homework assignments are reviewed by the health visitors at the start of each session.

It is not a requirement of the EPaS programme to complete all three phases of the programme, since the first phase may be sufficient on its own for some families. However, there are recommended number of sessions for each phase that implementers can use as a guide: three assessment sessions, one case analysis session, and between six and eight intervention sessions. The number of sessions completed depends on the complexity of the problem(s) being targeted. Sessions are normally conducted on a weekly basis but it was up to the health visitors to arrange appointments to implement the sessions.

\section{Measures}

\section{Sociodemographic measures}

A questionnaire was developed for health visitors asking the following demographic questions: age, gender, and number of years working as a health visitor.

A revised version of the Personal Data and Health Questionnaire (Hutchings 1996) was used to collect 
baseline family demographics. The questionnaire covers key socioeconomic circumstances (e.g., education, marital status, income, employment status). Education was dichotomised to represent low (left school before or at 16 years of age) or high (left school after 16 years of age); Living in poverty was dichotomised to represent low (income less than $60 \%$ median) or high (income above $60 \%$ median) based on figures from Office for National Statistics (2014). A socio-economic risk index was also calculated based on categories from Hutchings (1996) and Rutter and Quinton (1977). These were: unemployment, single parent, teenage parent ( $<20$ years of age) at birth of first child, low education, living in poverty, and symptoms of depression indicated by scoring borderline or above on the Beck Depression Inventory II (Beck et al. 1996). High risk is indicated by the presence of three or more risk factors.

\section{Eyberg Child Behaviour Inventory}

The ECBI is a 36-item, parent-reported inventory designed to assess the frequency and intensity of behavioural problems in children aged 2 to 16 years. The questionnaire consists of two subscales with clinical cut-offs: Intensity $(\geq 131)$ and Problem $(\geq 15)$. Higher scores indicate more behaviour problems. The internal consistency across the two time points in the present study was good (Intensity: baseline $\alpha=0.88$ and follow-up $\alpha=0.95$; Problem: baseline $\alpha=0.81$ and follow-up $\alpha=0.93$ ).

\section{Conners Abbreviated Parent-Teacher Questionnaire (Abbreviated Conners)}

The Abbreviated Conners is a 10 -item inventory used to measure symptoms of child hyperactive behaviour (Conners 1994). Higher scores indicate more behaviour problems. The internal consistency for the present study was good (Baseline $\alpha=0.85$ and follow-up $\alpha=0.87$ ).

\section{The Parenting Scale (PS)}

The PS is a 30-item, parent-reported inventory used to assess dysfunctional parenting practices (Arnold et al. 1993). As well as a total score, there are three subscales: Laxness, Over-reactivity, and Verbosity. Higher scores indicate higher dysfunctional parenting. The internal consistency for the total score and each subscale were as follows: total (baseline $\alpha=0.87$ and follow-up $\alpha=0.92$ ); laxness (baseline $\alpha=0.89$ and follow-up $\alpha=0.93$ ); overreactivity (baseline $\alpha=0.82$ and follow-up $\alpha=0.85$ ); verbosity (baseline $\alpha=0.52$ and follow-up $\alpha=0.67$ ). Because of the low internal consistency for the verbosity subscale, it was not used in the analyses.
Beck Depression Inventory II (BDI-II)

The BDI-II is a 21-item, parent-reported measure of depressive symptomatology (Beck et al. 1996). Higher scores indicate more symptoms of depression. The internal consistency for the present study was good (baseline $\alpha=$ 0.92 and follow-up $\alpha=0.95$ ).

\section{Parent satisfaction}

A questionnaire was developed to measure parent satisfaction with the programme. Questions asked about programme content (7 questions), overall process (2 questions), and health visitor (1 question). Responses were on a fivepoint Likert scale from Very unhelpful to Very helpful. Parents were also asked if they would recommend the programme to other parents. Higher scores represent more satisfaction. This questionnaire was collected by health visitors at their final session with the parent.

\section{Parent-child observation}

An observation of parent-child interaction was conducted using categories from the Dyadic Parent-Child Interaction Coding System (Eyberg and Robinson 1981). This measure uses a frequency count of observed behaviours over a 30-minute time period. Parents were asked to play with their child as they normally would. The categories used included: Observed positive parenting, observed social-emotional coaching, and observed negative parenting. All parentchild observations were live coded by one of two trained coders who were unaware of which condition parents had been allocated. Inter-rater reliability was examined for over $20 \%$ of observations at each time point (baseline $=24.1 \%$; follow-up $=29.3 \%$ ). For the current study, overall intraclass correlations (ICC) for the categories were as follows: Observed positive parenting ICC $=0.950$; Observed socialemotional coaching ICC $=0.961$; Observed negative parenting ICC $=0.933$.

\section{Data Analyses}

\section{Feasibility outcomes}

Follow-up retention rates are reported as percentages. Any differences in demographic characteristics and baseline scores between families lost to follow-up and those who remained in the study were explored using independent $t$ tests and chi-square tests. Programme delivery was explored by examining the percentage of parents that received each of the three EPaS phases and mean number of sessions received. Mean percentages from the parent satisfaction questionnaire are reported. 


\section{Initial effectiveness}

All data analyses were completed using SPSS version 24. Variable residuals were examined using P-P plots to detect any violations in normality. Four variables, namely BDI-II, observed positive parenting, observed social-emotional coaching, and observed negative parenting were found to violate normality assumptions, and were therefore normalised using square-root transformations. The square-rooted values were used in the analyses. To account for missing data at follow-up, analyses were conducted using last observation carried forward. Repeated measures ANOVA models were conducted with time as the within-group variable and condition as the between-group variable. Effect sizes were calculated by dividing the model estimate with the pooled standard deviation at baseline. Interpretation was based on Cohen's $d$ values (Cohen 1988).

\section{Results}

\section{Study Retention}

Twenty-two families (38\%) were lost to the six-month follow-up, ten (34\%) intervention and 12 (41\%) TAU families (see Fig. 1). For the ten intervention families, nine could not be contacted at follow-up and one had moved. For the 12 TAU families, nine withdrew because of reported improvements in their child's behaviour when contacted by researchers at follow-up, two had moved, and one withdrew because of a long-term illness. There were no significant differences between those lost to follow-up and those not lost in terms of demographic characteristics or baseline data $(p>0.05)$.

Table 2 Descriptive statistics for intervention and control

\section{Programme Delivery}

Of the 29 families in the intervention condition, 27 (93\%) of the families completed the assessment phase, $18(62 \%)$ completed the assessment and case analysis phase and 15 $(51.7 \%)$ completed all three phases of the EPaS programme. No data were available for two families. The mean number of home visits for the intervention families was 6.91 ( $S D=$ 2.75 , range $=2-12$ ).

Because the control group was TAU, some families $(n=$ $7 ; 24 \%$ ) also received visits from their health visitor for support for their child's behavioural challenges $(M=1.26$, $S D=2.90$, range $=0-13)$. Five received generic behavioural support, one was referred to the Triple-P programme, and one received an intensive support package delivered by a family support worker alongside the health visitor.

\section{Participant Satisfaction}

Families in the intervention condition were asked to complete a satisfaction questionnaire about the intervention at the final session with their health visitor. Fifteen families (52\%) completed this, 13 of whom had completed all three phases of EPaS and two who had completed the assessment and case analysis phases. Satisfaction levels were high with $96 \%$ rating different aspects of the intervention as helpful (range 80-100\%). Ninety-three per cent would recommend the programme to other parents.

\section{Initial Effectiveness}

Descriptive statistics are displayed in Table 2. Results from the repeated measures ANOVA models can be seen in

\begin{tabular}{|c|c|c|c|c|c|c|c|c|}
\hline & \multicolumn{4}{|c|}{ TAU, WL Control } & \multicolumn{4}{|c|}{ Intervention } \\
\hline & \multicolumn{2}{|c|}{ Baseline } & \multicolumn{2}{|c|}{ Follow-up } & \multicolumn{2}{|c|}{ Baseline } & \multicolumn{2}{|c|}{ Follow-up } \\
\hline & $n$ & $M(S D)$ & $n$ & $M(S D)$ & $n$ & $M(S D)$ & $n$ & $M(S D)$ \\
\hline ECBI intensity & 29 & $163.07(27.56)$ & 17 & $169.82(38.08)$ & 29 & $167.62(30.07)$ & 19 & $144.53(40.53)$ \\
\hline ECBI problem & 29 & $20.31(5.29)$ & 17 & $20.12(7.96)$ & 29 & $20.31(6.01)$ & 18 & $14.22(9.81)$ \\
\hline Conners & 29 & 21.47 (4.97) & 17 & $21.00(5.43)$ & 29 & $20.90(5.60)$ & 19 & $17.79(6.70)$ \\
\hline PS laxness & 29 & $3.21(1.23)$ & 17 & $3.11(1.30)$ & 29 & $3.23(1.32)$ & 19 & $2.86(1.39)$ \\
\hline PS overreactive & 29 & $2.84(0.76)$ & 17 & $2.75(1.01)$ & 29 & $2.47(1.04)$ & 19 & $2.27(0.85)$ \\
\hline PS total & 29 & $3.24(0.71)$ & 17 & $3.22(0.94)$ & 29 & $3.14(0.89)$ & 19 & $2.84(0.86)$ \\
\hline BDI-II & 29 & $21.01(11.64)$ & 17 & $19.68(13.80)$ & 29 & $19.05(11.36)$ & 19 & $15.21(13.95)$ \\
\hline Positive parent ${ }^{\mathrm{a}}$ & 29 & $26.93(23.12)$ & 16 & $17.75(17.05)$ & 29 & $20.21(13.64)$ & 19 & $22.11(14.17)$ \\
\hline SE coaching ${ }^{a}$ & 29 & $104.90(52.28)$ & 16 & $85.88(56.53)$ & 29 & $108.41(74.20)$ & 19 & 91.53 (14.17) \\
\hline Negative parent ${ }^{\mathrm{a}}$ & 29 & $19.45(17.66)$ & 16 & $16.25(12.01)$ & 29 & $16.38(11.01)$ & 19 & $12.74(7.83)$ \\
\hline
\end{tabular}

$T A U$ treatment as usual, $W L$ waitlist, ECBI Eyberg Child Behavior Inventory, Conners abbreviated conners, PS Parenting Scale. BDI-II Beck Depression Inventory II

${ }^{\mathrm{a}}$ Observed outcomes 
Table 3 Results of repeated measures ANOVA models

\begin{tabular}{|c|c|c|}
\hline Outcomes & Estimate $(95 \% \mathrm{CI})$ & Effect size $(95 \% \mathrm{CI})$ \\
\hline \multicolumn{3}{|c|}{ ECBI intensity } \\
\hline Condition & $-3.59(-18.99,11.82)$ & $-0.13(-0.66,0.41)$ \\
\hline Time & $-6.83(-14.02,0.37)$ & $-0.24(-0.49,0.01)$ \\
\hline \multicolumn{3}{|c|}{ ECBI problem } \\
\hline Condition & $-1.55(-4.70,1.60)$ & $-0.28(-0.84,0.29)$ \\
\hline Time & $-2.24(-3.95,-0.53)^{*}$ & $-0.40(-0.70,-0.09)^{*}$ \\
\hline \multicolumn{3}{|c|}{ Abbreviated conners } \\
\hline Condition & $-1.35(-4.11,1.41)$ & $-0.26(-0.78,0.27)$ \\
\hline Time & $-1.64(-2.79,-0.48)^{*}$ & $-0.31(-0.53,-0.09)^{*}$ \\
\hline \multicolumn{3}{|l|}{ PS laxness } \\
\hline Condition & $-0.08(-0.70,0.54)$ & $-0.06(-0.56,0.43)$ \\
\hline Time & $-0.21(-0.38,-0.05)^{*}$ & $-0.17(-0.30,-0.04)^{*}$ \\
\hline \multicolumn{3}{|c|}{ PS overreactive } \\
\hline Condition & $-0.40(-0.86,0.07)$ & $-0.43(-0.93,0.08)$ \\
\hline Time & $-0.04(-0.19,0.12)$ & $-0.04(-0.21,0.13)$ \\
\hline \multicolumn{3}{|l|}{ PS total } \\
\hline Condition & $-0.20(-0.60,0.20)$ & $-0.25(-0.75,0.25)$ \\
\hline Time & $-0.12(-0.25,0.01)$ & $-0.15(-0.32,0.01)$ \\
\hline \multicolumn{3}{|l|}{ BDI-II } \\
\hline Condition & $-0.30(-1.01,0.42)$ & $-0.22(-0.73,0.30)$ \\
\hline Time & $-0.30(-0.59,-0.01)^{*}$ & $-0.22(-0.42,-0.01)^{*}$ \\
\hline \multicolumn{3}{|c|}{ Observed positive parent } \\
\hline Condition & $-0.17(-0.98,0.64)$ & $-0.10(-0.58,0.38)$ \\
\hline Time & $-0.21(-0.63,0.21)$ & $-0.12(-0.37,0.12)$ \\
\hline \multicolumn{3}{|c|}{ Observed SE coaching } \\
\hline Condition & $0.01(-1.47,1.49)$ & $0.003(-0.50,0.51)$ \\
\hline Time & $-0.49(-0.98,0.00)$ & $-0.17(-0.33,0.00)$ \\
\hline \multicolumn{3}{|c|}{ Observed negative parent } \\
\hline Condition & $-0.22(-0.98,0.55)$ & $-0.14(-0.61,0.34)$ \\
\hline Time & $-0.13(-0.41,0.16)$ & $-0.08(-0.25,0.10)$ \\
\hline
\end{tabular}

ECBI Eyberg Child Behavior Inventory, Conners abbreviated conners, $P S$ Parenting Scale, BDI-II Beck Depression Inventory II $* p<0.05$

Table 3. There was a significant main effect of time for ECBI Problem, Abbreviated Conners, PS laxness, and BDIII indicating a reduction in scores from baseline to followup with small effect sizes. There was no significant effect of condition with all confidence intervals crossing zero. However, there were small effect sizes favouring the intervention condition for ECBI Problem, Abbreviated Conners, PS over-reactivity, PS total, and BDI-II.

\section{Discussion}

This study explored the feasibility of delivering an individually administered parenting programme within existing health visiting services. The feasibility of delivering the
$\mathrm{EPaS}$ programme in its current form within existing health visiting services is questionable and requires further examination. There was limited evidence of programme effectiveness; however, the results should be interpreted in context due to a number of challenges.

The results of the analyses indicated that child behaviour problems, lax parenting, and parental depression significantly reduced over time for the whole sample. However, there was no significant difference between families in the intervention and TAU control conditions at follow-up. The significant whole group results should be interpreted with caution since they may be due to regression to the mean (Barnett et al. 2004). There was some evidence of a stronger effect on several key measures for families in the intervention condition based on small effect sizes; however, the differences were not significant. There is increased variability in the scores at follow-up, reflected by larger standard deviations, suggesting a large range of change in scores. This may be why some of the reductions in scores seen in the intervention condition were not significant changes. The lack of differences between conditions may also be due to the TAU nature of the control condition or the flawed design whereby each health visitor identified two families with whom to work, one randomised into the intervention and the other to the control condition. This means that parents in the control condition still had access to their health visitor if needed. The design was implemented due to restrictions in time and resources and in order to try to maximise the recruitment of families. It also meant that the training only had to be delivered to one set of health visitors who could then implement the programme with their families. Records kept by health visitors to monitor visits showed that seven families from the TAU control condition did receive support from their health visitor during the intervention phase. It is not possible to know whether the health visitors used some of the skills taught in the $\mathrm{EPaS}$ training with their control families. Another possibility to the lack of between-group differences is that the families in each condition were not equivalent at follow-up. As previously mentioned, there were no significant differences between conditions in terms of demographics and baseline characteristics; however, the CONSORT diagram shows that nine families in the control condition dropped out because of child behaviour improvements. This was not the case for those who dropped out of the intervention condition, indicating differential attrition.

Delivery of the programme was acceptable with $93 \%$ of families completing the assessment phase. It is not a requirement of the $\mathrm{EPaS}$ programme that parents must complete all three phases. It is possible that the assessment phase alone may have been enough to elicit changes for some families, as found in the Family Check-Up intervention (FCU; Dishion et al. 2008; Shaw et al. 2006) in which 
families undergo three sessions of assessment based on motivational interviewing techniques and are offered additional follow-up sessions if needed. The FCU programme has shown significant results for child behaviour problems (Dishion et al. 2008) with maintenance effects up to 7.5 years (Dishion et al. 2014), but some parents do not opt for the follow-up sessions, indicating that the assessment is sufficient for them to recognise more effective parenting strategies. This may have been why some parents in the present study did not complete all three phases of the EPaS programme.

Parents reported high rates of satisfaction with the EPaS programme suggesting that the programme is acceptable to families of young children with behaviour problems. An earlier paper on the outcomes for health visitors also showed high rates of programme acceptability (Williams and Hutchings 2018). However, the results should be interpreted with caution. In the current study, parent satisfaction was collected using a self-report questionnaire during the final EPaS session with their health visitor. The ratings may be subject to participant response bias since parents may have felt pressured to give positive responses to please their health visitor. Also, only $52 \%$ of the intervention families returned the satisfaction questionnaire. Qualitative interviews with an independent researcher would have been more useful since they would provide a richer source of data and reduce the risk of bias.

\section{Challenges}

Recruitment for the trial was more difficult than expected. Recruitment difficulties in RCTs are not unusual and are well documented, with an estimated $60 \%$ of RCTs failing to reach recruitment targets (McDonald et al. 2006; Robinson et al. 2016; Watson and Torgerson 2006). The planned sample size was 60 health visitors and 120 families; however, only 29 health visitors and 58 families participated in the study. Preliminary meetings with health visiting managers during study inception were positive and managers reported that the planned study would be feasible. After commencement of the study, the reorganisation of tier 1 services in the health service, including the role of health visitors, was announced and implemented. This may have affected health visitors' abilities to dedicate time to participating in the research study. Difficulties in identifying eligible families for the study were also unexpected although those identified were reporting, on average, very significant problems with their children. In a similar trial conducted by Hutchings et al. (2007) health visitors identified over 200 families, with young children displaying clinical levels of behaviour problems. That trial targeted a similar population from similar areas as the current trial, used similar eligibility criteria, but only used health visitors to identify families not to implement the intervention. Seventy-four percent of families identified met the eligibility criteria and 93.3\% consented to take part (Hutchings, Bywater and Daley 2007). This is in contrast to the current trial whereby only 87 families were identified, $87 \%$ met the eligibility criteria, and $67 \%$ consented to participate. The lower numbers of identified families may be partly due to the creation of government schemes such as the Welsh Government Flying Start programme, specifically targeting young children aged 2 and 3 years with additional support including parent groups, language and play sessions, and enhanced health visiting support (Welsh Government 2016).

Retention at the six-month follow-up was poor with only $62 \%$ of families providing data. There were no significant differences between families lost at follow-up and those who remained in the study, and drop-outs were relatively evenly distributed across the conditions (10 intervention and 12 control families). Other studies have found a number of predictors associated with lower retention. These include demographic characteristics such as low socioeconomic status, unemployment, low education, single parent status, younger maternal age, and ethnic minority status (e.g., Fernandez and Eyberg 2009; Reyno and McGrath 2006; Robinson et al. 2016). The families in the current study showed high rates of poverty, unemployment, and low education with two-thirds of the sample reporting three or more socioeconomic risk factors. When taking into account the level of disadvantage in the sample, the attrition rate is similar to other studies of individually delivered parenting programmes (e.g., 39\% in Fernandez and Eyberg 2009; $49 \%$ in Werba et al. 2006).

Another factor that may have influenced retention and recruitment could be health visitor inexperience. The median time working as a health visitor was three years. This was very different from the Lane and Hutchings (2002) evaluation of the EPaS programme in which health visitors reported means of between 9 and 11 years' experience. The relationship between health visitors and their clients is of utmost importance, especially when working with vulnerable families, in order to develop an understanding of the family circumstances and when introducing intervention programmes (Whittaker 2014). Vulnerable families are much harder to engage in intervention programmes (Lavigne et al. 2010; Reyno and McGrath 2006). Because many of the health visitors were relatively inexperienced, it is possible that they may not have developed the skills needed to form strong, trusting relationships with parents on their caseloads which may have impacted on parents' engagement with the intervention. The health visitors also lacked experience in delivering evidence-based behavioural interventions since this was the first time they had delivered the EPaS programme. A survey of their skills showed that they used evidence-based techniques as part of their work 
with families (see Williams and Hutchings 2018); however, the rates were very variable with some using many techniques and others using very few. This means that more experienced health visitors may be better equipped to deliver the intervention. There are also issues around health visitor competence to consider. This was the first time that the health visitors had delivered the EPaS programme. Many RCTs ensure that facilitators have delivered the programme at least once before implementing as part of research (Hutchings, Bywater and Daley 2007), however this was not possible for the current trial. There are also questions around health visitor inexperience, as described above, meaning that some may not have had the skills to deliver the intervention with fidelity. There were no eligibility criteria based on the health visitors' experience. It is also possible that health visitors' prior learning and behaviour/expectations may have affected the way they delivered the intervention which, in turn, may have affected the results. Nevertheless, overall, families in both the intervention and control conditions showed significant improvements in child behaviour, lax parenting, and parental mental health.

Implementation fidelity is the degree to which an intervention is delivered as intended by the developer. It encompasses not only adherence to the intervention manual but also facilitator competence in terms of components of the intervention and clinical skills (McMahon and Pasalich 2018). The implementation of a programme can have significant effects on outcomes (Kaminski et al. 2008; McMahon and Pasalich 2018), therefore monitoring implementation fidelity is important. For the current study, all health visitors received a detailed intervention manual and three days of training. The training sessions were delivered one month apart which enabled some supervision as part of the training process; however, clinical supervision sessions on individual cases were not available. The lack of clinical supervision is particularly problematic since it is an important aspect of any intervention delivery (Flay et al. 2005) and may have affected health visitors' abilities to effectively apply the intervention. Clinical supervision had been intended and agreed upon by the collaborating services involved in the project; local clinical psychologists were going to provide supervision within their locality; however, due to scheduling difficulties, this did not happen (with the exception of one site). This is a significant limitation, particularly given the high levels of need within the families recruited, and has implications for the interpretation of the results.

Childhood behaviour difficulties are a significant problem not only to families but also society. Without social learning theory-based intervention, these problems can lead to long-term poor outcomes for children (NCCMH 2013). Group based parenting programmes are effective but not always accessible, especially for vulnerable families
(Lavigne et al. 2010). Individually delivered programmes are more effective for hard to engage, vulnerable parents who often have complex problems that require individually focussed interventions (Lundahl et al. 2006). In the UK, health visitors provide parenting support as part of their universal access to families of children under 5 years of age (Myors et al. 2014). They are good at identifying families of children with behaviour problems (Hutchings et al. 2007), but with recent changes to their role, they may not have the time or relevant training to deliver social learning theorybased programmes.

The EPaS programmes contains components of effective interventions (e.g., live coaching, social learning theory principles, homework assignments; Kaminski et al. 2008). Previous evaluations of the EPaS programme reported positive outcomes (Hutchings et al. 2002, 2004; Hutchings and Williams 2013; Lane and Hutchings 2002), but the programme required adaptations to the training format. The results of the current study are promising, with good rates of acceptability for parents and health visitors (see Williams and Hutchings 2018), but limited evidence of effectiveness. It is clear that the roles of health visitors have significantly changed since the earlier trial (Lane and Hutchings 2002), with less time available for attending training, conducting research related activities, and systematic support for families. This suggests that health visitors may not be the best choice as facilitators. The original version of the EPaS programme was developed for CAMHS-based workers working with children with severe behaviour problems (Hutchings et al. 2002). It was later developed for use by health visitors due to the limited accessibility to families when delivered through CAMHS. However, health visitor time restraints and lack of clinical supervision in the current study meant that they struggled to identify and engage families in the intervention. Given the risks of poor longterm outcomes for children with early onset behaviour problems, this suggests the importance of targeting a different facilitator population (e.g., CAMHS-based primary care workers) for the programme to be delivered as intended.

\section{Limitations and Future Research Directions}

This study has a number of limitations. First, the sample size was very small and the attrition rate at follow-up was high with $38 \%$ of families lost to follow-up. Second, data were not collected on any services used by the families in the TAU control condition. It is possible that control family access to other services may have contributed to the lack of significant differences between conditions. Third, there may have been a knowledge contamination effect due to the fact that health visitors were trained in the EPaS programme but had access to the control families as part of TAU. Fourth, 
the randomization did not result in equivalent groups, leading to differential attrition which may have affected the between-group results. Also, due to scheduling difficulties, clinical supervision for the participating health visitors by primary care clinical psychologists did not happen.

The results of this feasibility trial suggest some future directions. First, an exploration of different recruitment strategies is warranted to try to maximise the number of families being identified. Lack of time was a significant barrier for health visitors in participating in the trial and also identifying families from their caseloads. It is possible that utilising other services, such as the Welsh Governmentfunded Flying Start Initiative, may be a better way of identifying parents. Second, further feasibility work around retention strategies would also be useful because of the high attrition level at follow-up. Robinson et al. (2015) identify a number of retention strategies used in RCTs, some of which were not used in this study. For example, financial incentives are commonly used, with over half the studies identified in the Robinson et al. (2015) review utilising them. The current study utilised a non-financial incentive in the form of a children's book for research participation. It is possible that the use of a financial incentive would have been more effective at retaining parents in the research at follow-up, especially since the level of disadvantage was high. Finally, health visitors struggled with time restrictions within their roles and there were questions around competency to deliver the intervention with high fidelity. Therefore, future research should explore whether other staff (e.g., CAMHS-based primary care workers) would be better placed to deliver the EPaS programme.

Acknowledgements The authors thank the health visitors and families who took part in the study.

Authors' Contributions MEW: designed and executed the study, conducted data analyses, and wrote the paper. $\mathrm{ZH}$ : assisted with data analyses and collaborated with writing of the study. DAO: assisted with executing the study (data collection) and collaborated in the writing of the final manuscript. JH: designed and assisted in executing the study, collaborated in the writing and editing of the final manuscript.

Funding This work was funded directly by an anonymous donation and coordinated through the Development and Alumna Relations Office, Bangor University. The funder had no involvement in the conduct of the research and/or preparation of the article.

\section{Compliance with Ethical Standards}

Conflict of Interest M.E.W., Z.H., and D.A.O. declare that they have no competing interests. J.H. is the developer of the EPaS programme and provides training through Early Intervention Wales Training Ltd.

Ethical Approval Ethical approval was granted by Bangor University School of Psychology Ethics Committee in May 2014, application number: 2014-12886, and the North West Wales Research Ethics Committee in July 2014, application number: 14/WA/0187. All procedures performed in the study were in accordance with the APA ethical standards in the treatment of the study sample.

Informed Consent Informed written consent was obtained from all individual participants included in the study.

Publisher's note Springer Nature remains neutral with regard to jurisdictional claims in published maps and institutional affiliations.

Open Access This article is distributed under the terms of the Creative Commons Attribution 4.0 International License (http://crea tivecommons.org/licenses/by/4.0/), which permits unrestricted use, distribution, and reproduction in any medium, provided you give appropriate credit to the original author(s) and the source, provide a link to the Creative Commons license, and indicate if changes were made.

\section{References}

Arnold, D. S., O’Leary, S. G., Wolff, L. S., \& Acker, M. M. (1993). The Parenting Scale: a measure of dysfunctional parenting in discipline situations. Psychological Assessment, 5, 137-144. https://doi.org/10.1037/1040-3590.5.2.137.

Barlow, J., \& Coren, E. (2018). The effectiveness of parenting programs: a review of Campbell reviews. Research on Social Work Practice, 28, 99-102. https://doi.org/10.1177/1049731517725184.

Barnett, A. G., Van Der Pols, J. C., \& Dobson, A. J. (2004). Regression to the mean: what it is and how to deal with it. International Journal of Epidemiology, 34, 215-220. https://doi. org/10.1093/ije/dyh299.

Barth, R. P., \& Liggett-Creel, K. (2014). Common components of parenting programs for children birth to eight years of age involved with child welfare services. Children and Youth Services Review, 40, 6-12. https://doi.org/10.1016/j.childyouth. 2014.02.004.

Beck, A. T., Steer, R. A., \& Brown, G. K. (1996). Manual for the Beck Depression Inventory-II. San Antonio: Psychological Corporation.

Brook, J., \& Salmon, D. (2017). A qualitative study exploring parental perspectives and involvement in health visiting services during the Health Visitor Implementation Plan in the South West of England. Health and Social Care in the Community, 25, 349-356. https://doi.org/10.1111/hsc.12308.

Cohen, J. (1988). Statistical power analysis for the behavioural sciences. Hillsdale: Erlbaum.

Conners, C. K. (1994). The Conners rating scales: use in clinical assessment, treatment planning and research. In M. E. Maruish (Ed.), Use of psychological testing for treatment planning and outcome assessment (pp. 467-497). Hillsdale: Erlbaum.

Cowley, S., Caan, W., Dowling, S., \& Weir, H. (2007). What do health visitors do? A national survey of activities and service organisation. Public Health, 121, 869-879. https://doi.org/10. 1016/j.puhe.2007.03.016.

Cowley, S., Whittaker, K., Grigulis, A., Malone, M., Donetto, S., Wood, H., \& Maben, J. (2013). Why health visiting? A review of the literature about key health visitor interventions, processes and outcomes for children and families (Report No. 016 0058). London: National Nursing Research Unit.

Department of Health (2009). Healthy child programme: pregnancy and the first five years of life. London: Department of Health.

Dishion, T. J., Brennan, L. M., Shaw, D. S., McEachern, A. D., Wilson, M. N., \& Jo, B. (2014). Prevention of problem behaviour 
through annual family check-ups in early childhood: intervention effects from home to early elementary school. Journal of Abnormal Child Psychology, 42, 343-354. https://doi.org/10. 1007/s10802-013-9768-2.

Dishion, T. J., Shaw, D., Connell, A., Gardner, F., Weaver, C., \& Wilson, M. (2008). The family check-up with high-risk indigent families: preventing problem behaviour by increasing parents' positive behaviour support in early childhood. Child Development, 79, 1395-1414. https://doi.org/10.1111/j.1467-8624.2008.01195.x.

Duppong-Hurley, K., Hoffman, S., Barnes, B., \& Oats, R. (2016). Perspectives on engagement barriers and alternative delivery formats from non-completers of a community-run parenting program. Journal of Child and Family Studies, 25, 545-552. https://doi.org/10.1007/s10826-015-0253-0.

Eyberg, S. M., \& Robinson, E. A. (1981). Dyadic parent-child interaction coding system. Seattle: University of Washington.

Eyberg, S., Boggs, S. R., \& Reynolds, L. A. (1980). Eyberg Child Behaviour Inventory. Oregon: University of Oregon Health Sciences Center.

Fernandez, M. A., \& Eyberg, S. M. (2009). Predicting treatment and follow-up attrition in parent-child interaction therapy. Journal of Abnormal Child Psychology, 37, 431-441. https://doi.org/10. 1007/s10802-008-9281-1.

Flay, B. R., Biglan, A., Boruch, R. F., Castro, F. G., Gottfredson, D., Kellam, S., \& Ji, P. (2005). Standards of evidence: criteria for efficacy, effectiveness and dissemination. Prevention Science, 6 , 151-175. https://doi.org/10.1007/s11121-005-5553-y.

Furlong, M., McGilloway, S., Bywater, T., Hutchings, J., Smith, S. M., \& Donnelly, M. (2012). Behavioural and cognitivebehavioural group-based parenting programmes for early-onset conduct problems in children aged 3 to 12 years (Cochrane review). Cochrane Database for Systematic Reviews, 2, 1-362. https://doi.org/10.1002/14651858.CD008225.pub2.

Gach, E. J., Ip, K. I., Sameroff, A. J., \& Olson, S. L. (2018). Early cumulative risk predicts externalizing behavior at age 10: the mediating role of adverse parenting. Journal of Family Psychology, 32, 92-102. https://doi.org/10.1037/fam0000360.

Heath, S. M., Wigley, C. A., Hogben, J. H., Fletcher, J., Collins, P., Boyle, G. L., \& Eustice, S. (2018). Patterns in participation: factors influencing parent attendance at two, centre-based early childhood interventions. Journal of Child and Family Studies, 27, 253-267. https://doi.org/10.1007/s10826-017-0878-2.

Hoeve, M., Dubas, J. S., Eichelsheim, V. I., van der Laan, P. H., Smeenk, W., \& Gerris, J. R. M. (2009). The relationship between parenting and delinquency: a meta-analysis. Journal of Abnormal Child Psychology, 37, 749-775. https://doi.org/10.1007/s10802009-9310-8.

Hogg, R., Ritchie, D., de Kok, B., Wood, C., \& Huby, G. (2013). Parenting support for families with young children-a public health, user-focused study undertaken in a semi-rural area of Scotland. Journal of Clinical Nursing, 22, 1140-1150. https:// doi.org/10.1111/jocn.12185.

Hutchings, J. (1996). The personal and parental characteristics of preschool children referred to a child and family mental health service and their relation to treatment outcome (Unpublished doctoral dissertation). Bangor, UK: University of Wales.

Hutchings, J., Appleton, P., Smith, M., Lane, E., \& Nash, S. (2002). Evaluation of two treatments for children with severe behaviour problems: child behaviour and maternal mental health outcomes. Behavioural and Cognitive Psychotherapy, 30, 279-295. https:// doi.org/10.1017/S1352465802003041.

Hutchings, J., Bywater, T., \& Daley, D. (2007). Early prevention of conduct disorder: how and why did the North and Mid Wales Sure Start study work? Journal of Children's Services, 2, 4-14. https://doi.org/10.1108/17466660200700012.
Hutchings, J., Bywater, T., Daley, D., Gardner, F., Whitaker, C. J., Jones, K., \& Edwards, R. T. (2007). Parenting intervention in Sure Start services for children at risk of developing conduct disorder: pragmatic randomised controlled trial. British Medical Journal, 334, 678-684. https://doi.org/10.1136/bmj.39126. 620799.55.

Hutchings, J., Lane, E., \& Kelly, J. (2004). Comparison of two treatments for children with severely disruptive behaviours: a four-year follow-up. Behavioural and Cognitive Psychotherapy, 32, 15-30. https://doi.org/10.1017/S1352465804001018.

Hutchings, J., \& Williams, M. E. (2013). Report on the staff training project to support children with developmental challenges funded by the Waterloo Foundation. Bangor, UK: Children's Early Intervention Trust.

Hutchings, J., \& Williams, M. E. (2019). A practitioner's guide to enhancing parenting skills: assessment, analysis and intervention. Abingdon, Oxford: Routledge.

Kaminski, J. W., Valle, L. A., Filene, J. H., \& Boyle, C. L. (2008). A meta-analytic review of components associated with parent training program effectiveness. Journal of Abnormal Child Psychology, 36, 567-589. https://doi.org/10.1007/s10802-007-9201-9.

Kazdin, A. E. (1997). Parent management training: evidence, outcomes, and issues. Journal of the American Academy of Child and Adolescent Psychiatry, 36, 1349-1356. https://doi.org/10. 1097/00004583-199710000-00016.

Lane, E., \& Hutchings, J. (2002). Benefits of a course in behavioural analysis for health visitors. British Journal of Nursing, 11(10), $702-714$.

Lavigne, J. V., LeBailly, S. A., Gouze, K. R., Binns, H. J., Keller, J., \& Pate, L. (2010). Predictors and correlates of completing behavioural parent training for the treatment of oppositional defiant disorder in pediatric primary care. Behavior Therapy, 41, 198-211. https://doi.org/10.1016/j.beth.2009.02.006.

Lundahl, B., Risser, H. J., \& Lovejoy, M. C. (2006). A meta-analysis of parent training: moderators and follow-up effects. Clinical Psychology Review, 26, 86-104. https://doi.org/10.1016/j.cpr. 2005.07.004.

Martel, M. M. (2013). Sexual selection and sex differences in the prevalence of childhood externalising and adolescent internalising disorders. Psychological Bulletin, 130, 1221-1259. https:// doi.org/10.1037/a0032247.

McDonald, A. M., Knight, R. C., Campbell, M. K., Entwistle, V. A., Grant, A. M., Cook, J. A., \& Snowdon, C. (2006). What influences recruitment to randomised controlled trials? A review of trials funded by two UK agencies. Trials, 7, 9-16. https://doi.org/ 10.1186/1745-6215-7-9.

McMahon, R. J., \& Pasalich, D. S. (2018). Parenting and family intervention in treatment. In M. R. Sanders \& A. Morawska (Eds), Handbook of parenting and child development across the lifespan (pp. 745-773). Cham: Springer International Publishing AG.

Miner, J. L., \& Clarke-Stewart, A. (2008). Trajectories of externalising behaviour from age 2 to age 9: relations with gender, temperament, ethnicity, parenting, and rater. Developmental Psychology, 44, 771-786. https://doi.org/10.1037/0012-1649.44.3.771.

Munday, D. (2018). Caseload crunch. Community Practitioner, 91(9), 36-37.

Myors, K. A., Schmied, V., \& White, E. (2014). Child and family health nurses working with families of preschool-aged children. Journal of Clinical Nursing, 23, 181-190. https://doi.org/10. 1111/jocn.12249.

National Collaborating Centre for Mental Health. (2013). Antisocial behaviour and conduct disorders in children and young people: the NICE guideline on recognition, intervention, and management (Report No. 158). Leicester: RCPsych Publications. 
Office for National Statistics [ONS]. (2014). Households below average income: an analysis of the income distribution 1994/ 95-2012/13. London, UK: Department for Work and Pensions.

Polanczyk, G. V., Salum, G. A., Sugaya, L. S., Caye, A., \& Rohde, L. A. (2015). Annual research review: a meta-analysis of the worldwide prevalence of mental disorders in children and adolescents. Journal of Child Psychology and Psychiatry, 56, 345-365. https://doi.org/10.1111/jcpp.12381.

Reyno, S. M., \& McGrath, P. J. (2006). Predictors of parent training efficacy for child externalizing behaviour problems-a metaanalytic review. Journal of Child Psychology and Psychiatry, 47, 99-111. https://doi.org/10.1111/j.1469-7610.2005.01544.x.

Rivenbark, J. G., Odgers, C. L., Caspi, A., Harrington, H., Hogan, S., Houts, R. M., \& Moffit, T. E. (2018). The high societal costs of childhood conduct problems: evidence from administrative records up to age 38 in a longitudinal birth cohort. The Journal of Child Psychology and Psychiatry, 59, 703-710. https://doi.org/10.1111/ jcpp.12850.

Robinson, L., Adair, P., Coffey, M., Harris, R., \& Burnside, G. (2016). Identifying the participant characteristics that predict recruitment and retention of participants to randomised controlled trials involving children: a systematic review. Trials, 17, 294-310. https://doi.org/10.1186/s13063-016-1415-0.

Robinson, K. A., Dinglas, V. D., Sukrithan, V., Yalamanchilli, R., Mendez-Tellez, P. A., Dennison-Himmelfarb, C., \& Needham, D. M. (2015). Updated systematic review identifies substantial number of retention strategies: using more strategies retains more study participants. Journal of Clinical Epidemiology, 68, 1481-1487. https://doi.org/10.1016/j.jclinepi.2015.04.013.

Rutter, M., \& Quinton, D. (1977). Psychiatric disorder. Ecological factors and concepts of causation. In H. McGurk (Ed.), Ecological factors in human development (pp. 173-187). Amsterdam: North Holland.

Sayal, K., Tischler, V., Coope, C., Robotham, S., Ashworth, M., Day, C., Tylee, A., \& Simonoff, E. (2010). Parental help-seeking in primary care for child and adolescent mental health concerns: qualitative study. British Journal of Psychiatry, 197, 476-481. https://doi.org/10.1192/bjp.bp.110.081448.

Shaw, D. S., Dishion, T. J., Suplee, L., Gardner, F., \& Arnds, K. (2006). Randomized trial of a family-centred approach to the prevention of early conduct problems: 2-year effects of the Family Check-Up in early childhood. Journal of Consulting and Clinical Psychology, 74, 1-9. https://doi.org/10.1037/0022-006X.74.1.1.

Shaw, D. S., \& Shelleby, E. C. (2014). Early-starting conduct problems: Intersection of conduct problems and poverty. Annual Review of Clinical Psychology, 10, 503-528. https://doi.org/10. 1146/annurev-clinpsy-032813-153650.

Watson, J. M., \& Torgerson, D. J. (2006). Increasing recruitment to randomized trials: a review of randomized controlled trials. $B M C$ Medical Research Methodology, 6, 34-42. https://doi.org/10. 1186/1471-2288-6-34.

Welsh Government (2016). Evaluability assessment of Flying Start. Cardiff: Welsh Government. https://gov.wales/sites/default/files/ statistics-and-research/2019-07/161102-evaluability-assessmentflying-start-en.pdf

Werba, B., Eyberg, S. M., Boggs, S. R., \& Algina, J. (2006). Predicting the outcome of parent-child interaction therapy: success and attrition. Behavior Modification, 30, 618-646. https://doi.org/ 10.1177/0145445504272977.

Whittaker, K. (2014). Supporting parents and parenting practices: the health visiting context. Journal of Health Visiting, 2, 250-259. https://doi.org/10.12968/johv.2014.2.5.250.

Williams, M. E., \& Hutchings, J. (2018). Helping parents handle child behavioural problems. Community Practitioner, 91(8), 45-47.

Wilson, P., Furnivall, J., Barbour, R. S., Connelly, G., Bryce, G., Phin, L., \& Stallard, A. (2008). The work of health visitors and school nurses with children with psychological and behavioural problems. Journal of Advanced Nursing, 61, 445-455. https://doi. org/10.1111/j.1365-2648.2007.04505.x. 